\title{
A laminar flame investigation of 2-butanone, and the combustion-related intermediates formed through its oxidation
}

Christian Hemken ${ }^{1}$, Ultan Burke ${ }^{2}$, Isabelle Graf ${ }^{1}$, Lena Ruwe ${ }^{1}$, Sungwoo Park ${ }^{3}$, S. Mani Sarathy $^{3}$, K. Alexander Heufer ${ }^{2^{*}}$, Katharina Kohse-Höinghaus ${ }^{1^{*}}$

${ }^{1}$ Department of Chemistry, Bielefeld University, Universitätsstraße 25, D-33615 Bielefeld, Germany

${ }^{2}$ Physico-Chemical Fundamentals of Combustion, RWTH Aachen University, Schinkelstraße 8, D-52062 Aachen, Germany

${ }^{3}$ Clean Combustion Research Center, King Abdullah University of Science and Technology, Thuwal 23955-6900, Saudi Arabia

*Corresponding authors' email addresses: Katharina Kohse-Höinghaus: kkh@unibielefeld.de and Alexander Heufer: heufer@pcfc.rwth-aachen.de

\section{Abstract}

2-Butanone (methyl ethyl ketone) is a recently identified high-octane, next-generation biofuel candidate, synthesized through microbiological pathways from biomass. Its high octane number $(\mathrm{RON}=117)$, low boiling point $\left(80^{\circ} \mathrm{C}\right)$, and relatively high vapor pressure $\left(10.8 \mathrm{kPa}\right.$ at $\left.20^{\circ} \mathrm{C}\right)$ make 2-butanone a potentially good candidate for use in spark-ignition engines. The flame structure and species formed in 2-butanone combustion are of interest when further considering this compound for use as a fuel. To this end, the present study has, for the first time, quantitatively measured species profiles within a fuel-rich $(\phi=1.6)$ laminar premixed flat flame of 2-butanone. Two experiments which used different facilities and measurement techniques were combined to provide a cross comparison of the measured species. One experiment was performed using electron ionization (EI) molecularbeam mass spectrometry (MBMS), and the second relied on synchrotron-generated vacuum ultraviolet (VUV) photoionization (PI) MBMS. Quantitative mole fraction profiles for about 45 species were obtained from the two independent experiments that are found to be in good agreement. The experiments have identified the formation of a number of toxic 
oxygenated intermediates, such as methyl vinyl ketone (MVK), acetaldehyde, and formaldehyde. In addition, the measurements have also provided quantitative species profiles for a number of soot precursor species, the concentrations of which are notably low. These measurements provide useful validation targets for the further development of detailed chemical kinetic models. As a first test, an existing 2-butanone model was examined against the experimental data with the main aim to identify elements of the model that may need improvement.

Keywords: 2-butanone, methyl ethyl ketone, laminar premixed flame, molecular-beam mass spectrometry, oxygenated intermediates, soot precursor species 


\section{Introduction}

Rising global energy demand and adverse environmental impacts related to fossil-fuel combustion motivate a transition to a low-carbon energy system. Because of the dominant role of combustion in transportation, considerable effort is devoted to develop biofuels that may enable carbon savings and improved emission profiles. The combustion behavior of the biofuel classes of alcohols, esters and (cyclic) ethers has been investigated in some detail [1-3]. Depending on the conditions, such oxygenated fuels typically decrease the emission of unburned hydrocarbons, soot, and $\mathrm{CO}[2,4]$, but emission of carbonyl compounds may increase [5-7]. Recent research activities focus on fuels from cellulosic biomass to minimize competition with food production $[8,9]$. The expeditious incorporation of these next-generation biofuels into the existing transport infrastructure could be supported by accurate detailed/reduced chemical kinetic models that can predict their combustion characteristics. These models require experimental validation in order to evaluate their predictive capabilities $[10,11]$.

2-Butanone (methyl ethyl ketone) has been proposed as a promising biofuel, because it can be easily produced in two steps: Glucose can be microbiologically fermented by klebsiella oxytoca to 2,3-butanediol, which is catalytically converted to $90 \%$ 2-butanone [12]. Compared to standard gasolines 2-butanone has a high solubility in water and could thus leak into the groundwater upon spills. However it is relatively non-toxic with and $L D_{50, \text { oral }}$ of $3400 \mathrm{mg} / \mathrm{kg}$ [13]. Compared to diesel fuel its effective concentration $\mathrm{EC}_{50}[\mathrm{mg} \mathrm{HC/L}]$ is 1357, while that for Diesel is 0.16 [14].

2-Butanone's performance in a direct injection spark-ignition engine was recently compared to different other fuels, including a RON95 fuel blend, ethanol, and 2-methylfuran [15]. That study outlined the improvements 2-butanone yielded for soot, unburnt hydrocarbons, $\mathrm{NO}_{x}$ emissions, and improved mixture formation. 
Only few studies have been devoted to 2-butanone combustion chemistry. Decottignies et al. [16] have presented a mechanism for the combustion of 2-butanone added to a methane/air flame, based upon experiments using gas chromatography coupled with mass spectrometry. Shock tube ignition delay times and laminar burning velocities accompanied by a high-temperature detailed chemical kinetic model were provided in [17]. Theoretical calculations for the reactions of 2-butanone with $\mathrm{OH}$ and $\mathrm{HO}_{2}[18,19]$, and of 2-butanone3-yl with $\mathrm{O}_{2}$ [20] have been reported. Also, species time-histories in high-temperature pyrolysis of 2-butanone were analyzed in [21]. High-pressure ignition delay times and a modified detailed chemical kinetic model were recently presented in [22]. The first detailed chemical kinetic model that incorporates pathways in 2-butanone's low-temperature oxidation was reported by Burke et al. [23]; their study includes thermodynamic calculations for 2-butanone's oxidation species and further ignition delay time and laminar burning velocity measurements.

Missing in the literature is a detailed investigation of combustion intermediate and product species from 2-butanone combustion. The present work combines quantitative experiments in a laminar premixed low-pressure fuel-rich $(\phi=1.6)$ flame using electron ionization (EI) as well as photoionization (PI) molecular-beam mass spectrometry (MBMS). For the first time, quantitative mole fraction profiles of $\sim 45$ species were measured in these two independent flame experiments and thus provided an experimental cross check to reduce uncertainties in the quantification. The PI-MBMS measurements also served to identify isomers. The experiments have provided a wide array of intermediate species formed through the oxidation of 2-butanone in the flame. As an initial test, the detailed kinetic model of [23] was compared to the experimental results, including some modifications in fuel radical reactions. 


\section{Experiments}

Laminar premixed fuel-rich flames of 2-butanone/oxygen/argon $(0.113 / 0.388 / 0.50$ mole fraction) were investigated at 40 mbar, with a stoichiometry of $\phi=1.6$ and a cold-gas velocity of $2.574 \mathrm{~cm} / \mathrm{s}$ (at $298 \mathrm{~K}$ and $1 \mathrm{~atm}$ ). Experiments were performed with two fully independent arrangements in Bielefeld (EI-MBMS) and at the Advanced Light Source (ALS) in Berkeley (PI-MBMS). The combination is thought to minimize uncertainties related to different cross sections and calibration procedures in both facilities.

EI-MBMS experiments were performed in Bielefeld using an apparatus and evaluation procedures presented earlier [24]. The mass spectrometer provides high mass resolution of $m / \Delta m \approx 4000$ and permits detection of all species in the same mass spectrum due to a Gaussian energy distribution of $1 \mathrm{eV}$ (FWHM) of the ionizing electron beam. Intermediate species were detected at nominal energies of 11.0, 11.75, and $12.75 \mathrm{eV}$, and major species at $18 \mathrm{eV}$. From the flame stabilized on an in-house-built flat-flame burner, gas samples were obtained as a function of position via a quartz nozzle with a $25^{\circ}$ cone angle and $\sim 300 \mu \mathrm{m}$ orifice. An expansion sequence to $\sim 10^{-4} \mathrm{mbar}$ in the $1^{\text {st }}$ pumping stage and 10 ${ }^{6} \mathrm{mbar}$ in the ionization chamber minimized further reaction of the probed species. The data evaluation followed procedures in $[24,25]$, wherein quantitative concentrations were evaluated using argon as an internal reference and with calibration factors that combined all species-dependent parameters. Calibration factors were determined by cold-gas measurements of known gas compositions (direct), estimated by the RICS (relative ionization cross sections) method [26] or by simulating the signal (convolution, see [24]).

PI-MBMS flame experiments were performed at the ALS in Berkeley using synchrotrongenerated VUV radiation. Detailed information on the set-up and the experimental procedures are given elsewhere [27]. The set-up combines high mass and energy resolution of $m / \Delta m \approx 3500$ and $\Delta E= \pm 0.05 \mathrm{eV}$, enabling identification of isomers by their ionization potential (IP). Sampling was done by a quartz nozzle with a cone angle of $40^{\circ}$. 
Measurements were performed with energies between 8.7 and $16.6 \mathrm{eV}$ for soft ionization with low fragmentation and determination of isomeric species. Data evaluation relied on similar procedures as above and described in [25], using photoionization cross sections.

In all measurements, calibrated mass flow controllers with a maximal error of $5 \%$ were used. The syringe pump in the vaporizer system had an error of $0.5 \%$. Main species concentrations were determined within less than $15 \%$, and $20 \%$ uncertainty for $\mathrm{H}_{2}$. Intermediate species mole fractions carry a higher uncertainty with $<30 \%$ for directly calibrated species and factors of 2-4 for convolution and RICS procedures, depending on the calibration method and accuracy of available cross sections. Regarding such uncertainties, the combined PI- and EI-MBMS approach is of particular value.

The temperature profile was determined in the EI-MBMS set-up as described in [24] and calibrated in the exhaust gas at a height above the burner $h=20 \mathrm{~mm}$ by planar laserinduced fluorescence of $\mathrm{OH}$ using the set-up and procedure described in [28]. This calibration measurement with a result of $2160 \mathrm{~K}$ has an estimated uncertainty of $\pm 40 \mathrm{~K}$.

\section{Kinetic Modeling}

A recently developed chemical kinetic model [23], here called Version1, was utilized in order to test its predictive capabilities compared to the new flame speciation data presented here. This mechanism includes recent ab-initio thermodynamic calculations for all species related to 2-butanone oxidation, including 2-butanone, the three 2-butanoyl radicals, and further species formed through $\mathrm{O}_{2}$-addition to these radicals. The base mechanism in this model is the most recent version of the AramcoMech (Mech56.54) mechanism [29,30]. Version1 was compared to the new flame speciation measurements. To attempt improvement of the predictions, Version1 was then modified by adding reactions for radicalradical isomerization between the three fuel radicals (2-butanone-1-yl, 2-butanone-3-yl and 2-butanone-4-yl), resulting in Version2 (see Table S1), and leading to an improvement in 
the species predictions for the first primary intermediates. The rate constants for these reactions were assigned based on an analogy to alkanes [31]. The inclusion of these reactions changed the predictions of major product species from the decomposition of fuel radicals, highlighting the need for more detailed consideration of the fuel radical decomposition reactions and more accurate assignments of their rate constants to ultimately improve model predictions. Furthermore, the methyl-vinyl-ketone (MVK) submechanism was updated in Version2 by adopting that by Somers et al. [32].

All simulations were performed using the LOGEsoft [33] premixed burner-stabilized module. The experimentally determined temperature profile was included in the simulation while accounting for thermodiffusion and radiation, using a variable Lewis number transport model. The maximum number of grid points per unit curvature and gradient were 1.0 and 1.5 , respectively. The number of grid points used were 301 . Further comparisons of the model to existing experimental data in the literature [17,21-23] are available in the Supplemental Material (Figs. S4-S7). With the changes from Version1 to Version2, the model performance remains reasonably consistent with the literature data.

\section{Results and discussion}

The following analysis will provide information on the flame structure and will then focus particularly on intermediate species mole fractions, quantified in both experiments. These experimental results are also used as a guide to identify parameters in the model that would benefit from more detailed consideration.

\subsection{Main species}

Main species ( $\mathrm{Ar}, \mathrm{CO}, \mathrm{CO}_{2}, \mathrm{O}_{2}, \mathrm{H}_{2}, \mathrm{H}_{2} \mathrm{O}$, and 2-butanone) mole fractions are given in Fig. 1 . Excellent agreement is noted between PI- and El-MBMS measurements, especially when considering their fully independent determination. Because $\mathrm{H}_{2}$ was not detected at the ALS, the profile in the PI-MBMS evaluation is taken to be the same as in the EI-MBMS 
evaluation, normalizing the $\mathrm{H}_{2}$ signal to argon. Including $\mathrm{H}_{2}$ serves to decreases the total error in the species mole fractions. Mole fractions in the burned gas at $h=20 \mathrm{~mm}$ agree well with equilibrium calculations, shown at $24 \mathrm{~mm}$. The kinetic model simulations capture these profiles well. The experimental temperature profile used for the simulations is given in Fig. S1. Only simulations with Version2 are shown, since the quality of the prediction of the main species was similar with both models.

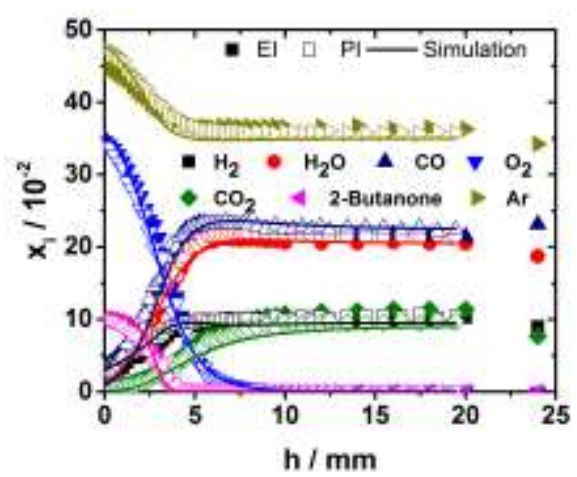

Figure 1: Main species profiles; symbols: filled: EI-MBMS, open: PI-MBMS, solid line: simulation with Version2.

\subsection{Reaction flux analysis}

Figure 2 shows a flux analysis with Version2, displaying the net percentage consumption (range $h=0-20 \mathrm{~mm}$ ) of each species. Some pathways are included with contributions $<1 \%$ to attempt to rationalize experimentally observed species. 2-Butanone is consumed through $\mathrm{H}$-abstraction reactions, forming the three fuel radicals (2-butanone-1-yl, 2-butanone-3-yl, and 2-butanone-4-yl, from left to right in Fig. 2). The 2-butanone-1-yl radical is consumed almost equally via $\beta$-scission and radical-radical isomerization forming 2-butanone-3-yl. 2-Butanone-3-yl is almost completely consumed through $\mathrm{C}-\mathrm{C} \beta$-scission resulting in $\mathrm{CH}_{3}$ and methylketene, and $<2 \%$ is consumed through either $\mathrm{C}-\mathrm{H} \beta$-scission forming MVK and $\mathrm{H}$-atom or through the concerted addition of $\mathrm{HO}_{2}$ and $\mathrm{O}-\mathrm{O}$ bond scission forming the related RO alkoxy radical species. Finally, 2-butanone-4-yl is primarily consumed through 
C-C $\beta$-scission, and $<2 \%$ of this radical forms MVK through $\mathrm{C}-\mathrm{H} \beta$-scission as the main production pathway for MVK.

The three fuel radicals, formed by $\mathrm{H}$-abstraction from the fuel molecule, could not be detected with the present PI-MBMS instrument. The first detectable intermediates, according to Fig. 2, should include ethyl $\left(\mathrm{C}_{2} \mathrm{H}_{5}\right)$ and ketene $\left(\mathrm{C}_{2} \mathrm{H}_{2} \mathrm{O}\right)$ as a result of $\mathrm{H}$-abstraction on the primary $\mathrm{C} 1$-atom (methyl group) and subsequent $\beta$-scission; methyl $\left(\mathrm{CH}_{3}\right)$ and methylketene $\left(\mathrm{C}_{3} \mathrm{H}_{4} \mathrm{O}\right)$ as a product of 2-butanone-1-yl $\beta$-scission; $\mathrm{MVK}\left(\mathrm{C}_{4} \mathrm{H}_{6} \mathrm{O}\right)$ from the pathways discussed above; and acetyl $\left(\mathrm{C}_{2} \mathrm{H}_{3} \mathrm{O}\right)$ and ethylene $\left(\mathrm{C}_{2} \mathrm{H}_{4}\right)$ from 2-butanone-4-yl decomposition. Further reactions of these primary products towards smaller molecules are expected to provide $\mathrm{CO}, \mathrm{HCO}, \mathrm{CH}_{3}$, and $\mathrm{C}_{2} \mathrm{H}_{3}$.

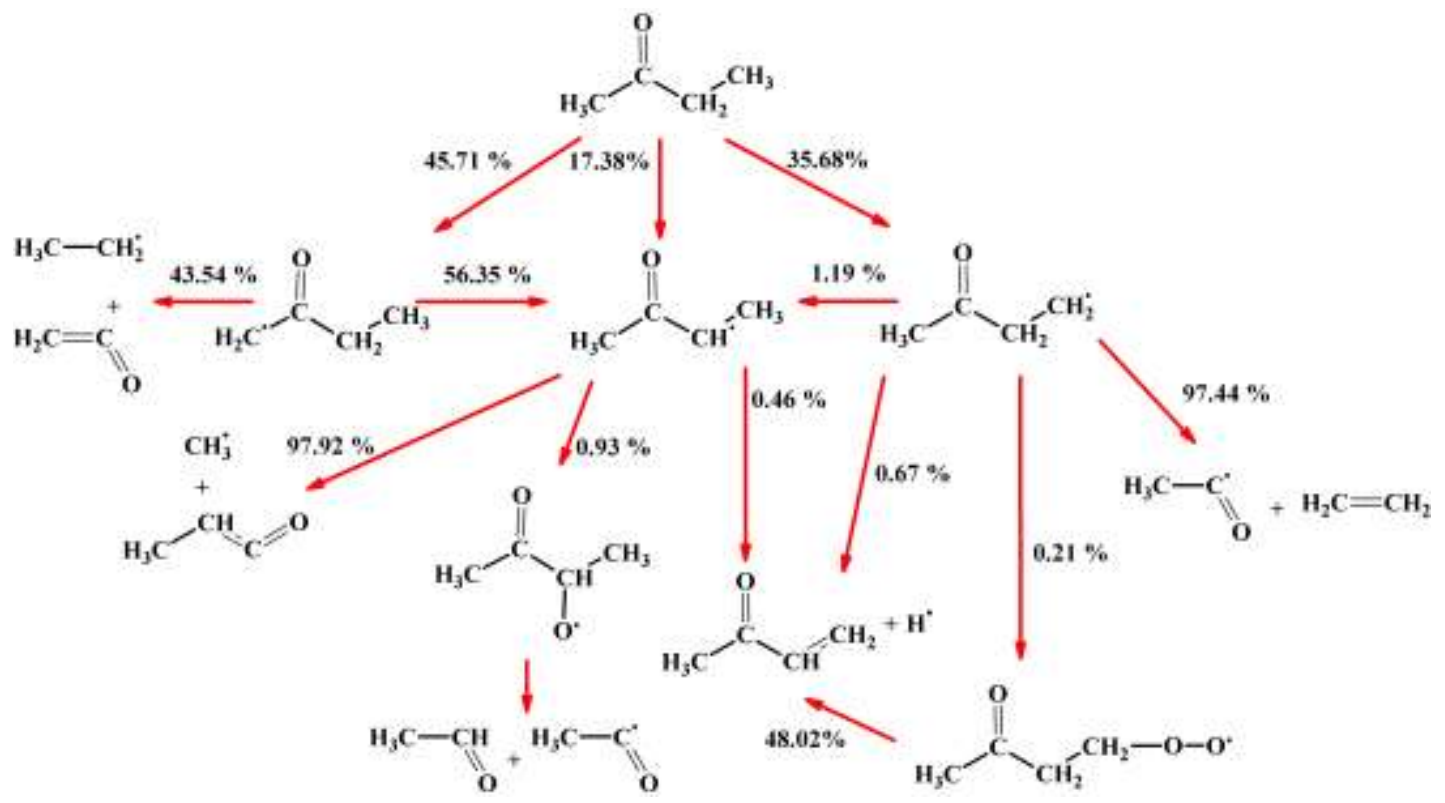

Figure 2: Reaction flux analysis for the flame condition; net consumption $(h=0-20 \mathrm{~mm})$ is shown as percentages next to the arrows.

\subsection{Primary intermediates}

Selected quantitative intermediate species profiles are provided in Figs. 3-5 (and Fig. S2) and maximum mole fractions for all measurements are given in Table S2. 
Figure 3 shows mole fractions for the first $\mathrm{H}$-abstraction/ $\beta$-scission products identified in Fig. 2. Notable is the overall very good agreement between both sets of measurements, with differences of the order of $10 \%$. $\mathrm{H}$-abstraction from the $\mathrm{C} 1$-atom leads to the formation of ketene with a maximum mole fraction (Fig. 3a) of $\sim 1.7 \times 10^{-3}$. The measured ketene mole fraction is over-predicted by Version1. Ketene is mainly a result of 2-butanone-1-yl decomposition. Including fuel-radical-specific reactions in Version2 improves the agreement with the measurements, probably because isomerization to 2-butanone-3-yl decreases the 2-butanone-1-yl mole fraction. The remaining discrepancy may be due to the rate constant for the $\beta$-scission of 2-butanone-1-yl. The corresponding scission product ethyl (Fig. 3b) is similarly over-predicted.
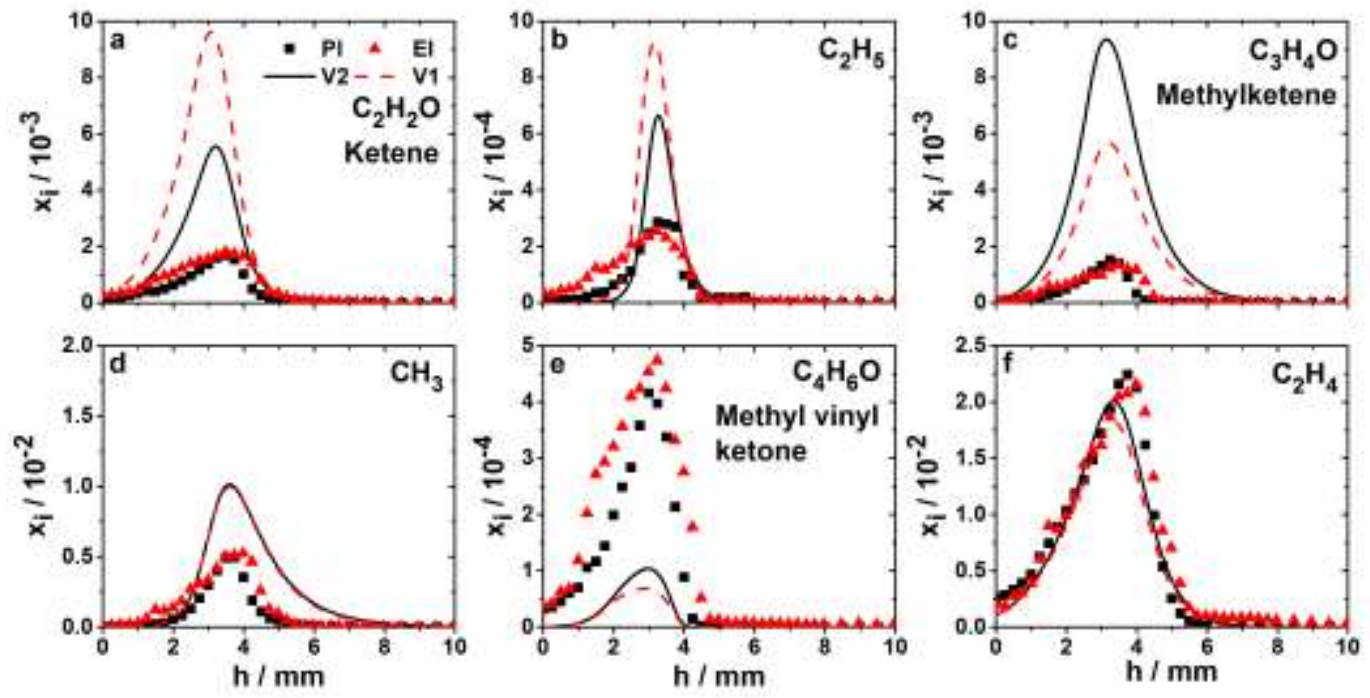

Figure 3: Mole fraction profiles of first detectable intermediates after $\mathrm{H}$-abstraction and $\beta$-scission. Symbols: PI- and EI-MBMS experiments, solid line: simulation with Version2; dashed line: Version1.

For methylketene and methyl (Figs. $3 \mathrm{c}$,d), peak concentrations of $1.5 \times 10^{-3}$ and $\sim 5 \times 10^{-3}$, respectively, are again in excellent agreement from both experiments. Both species are main $\beta$-scission products of 2-butanone-3-yl. Their mole fractions are over-predicted by factors of 3 and 2, respectively, by Version1. Using Version2 is no improvement for 
methylketene, while both model predictions are similar for $\mathrm{CH}_{3}$. A plausible reason for this behavior could be an incorrect prediction of the branching ratio between the destruction of 2-butanone-3-yl towards methylketene or MVK (see Fig. 2). $\mathrm{CH}_{3}$ might come from additional reactions with lesser influence of this branching ratio.

As noted earlier, MVK (Fig. 3e) should be formed mainly by decomposition of 2-butanone-4-yl, and in a lesser quantity from 2-butanone-3-yl, likely due to the weaker $\mathrm{C}-\mathrm{H}$ being broken in 2-butanone-4-yl decomposition compared to that of 2-butanone-3-yl. These are also the two most sensitive reactions for the formation of MVK (see Fig. S3, R1 and R2). A small amount is formed via a low-temperature pathway with $\mathrm{O}_{2}$ addition to the 2butanone-4-yl radical, followed by $\mathrm{HO}_{2}$ abstraction. The severe under-prediction of MVK is in accord with the potentially incorrect branching ratio for 2-butanone-3-yl destruction; however, the difference between Version1 and Version2 is not as pronounced as for methylketene since MVK is mainly formed via 2-butanone-4-yl. These assumptions are in agreement with a sensitivity analysis, showing the high sensitivity to the $\beta$-scission reactions of the fuel radicals (see Fig. S3, R19 and R20) as well as the lower sensitivity to the radical-radical isomerization reactions ( $R 8$ and $R 16)$. MVK formation is a critical point in the kinetic model, because MVK is a highly toxic species, $L D_{50, \text { oral }}=23.1 \mathrm{mg} / \mathrm{kg}$ [13] which is five times more toxic than formaldehyde, and it is thus important to understand its formation/consumption. At present, the model is not capable of predicting the experimental findings, and it is most likely that fuel radical decomposition pathways will need further consideration. Ethylene (Fig. 3f), formed mainly from the decomposition of ethyl and $\beta$ scission of 2-butanone-4-yl, is the most abundant intermediate, measured with both techniques to be $\sim 2.2 \times 10^{-2}$ and accurately reproduced by both models.

For the premixed flame conditions here, Version2 improves the performance for primary product prediction, except for methylketene which shows somewhat larger discrepancies. Production pathways predicted for methylketene are in general unimolecular (radical-radical 
isomerization and radical $\beta$-scission) and as such pressure-dependent. Currently, these reaction rate constants estimated in the model have no pressure dependence assigned to them. The current study therefore highlights that more detailed theoretical and/or experimental study of these elementary reactions should be performed to further reduce the uncertainty in their rate constants. In addition, a more detailed sub-mechanism for the oxidation of methylketene might help to improve the predictions of the intermediates presented here.

\subsection{Further species}

Regarding cleaner combustion, it is important to predict the formation of potentially harmful species. Even though the presence of toxic intermediates may be of limited importance in laminar reaction systems, since they might burn off, their formation might be interesting under turbulent conditions where small amounts of unburned hydrocarbons might be released. While ketene and methylketene are non-toxic, the formation of MVK is critical. Furthermore, oxygenated species such as aldehydes or specific alcohols could be of concern, as well as soot precursors including aromatic compounds.

Figure 4 shows the profiles of formaldehyde, acetaldehyde, and acetone. $\mathrm{The}^{\mathrm{C}} \mathrm{H}_{2} \mathrm{O}$ mole fraction is substantial at $\sim 4 \times 10^{-3}$ (Fig. 4a), with slight deviations between both experimental methods and reasonable model prediction. Acetaldehyde is formed directly and through vinyl alcohol from the decomposition of methylketene; it also results from the concerted elimination reaction of ethyl and molecular $\mathrm{O}_{2}$. The prediction of acetaldehyde is improved in Version2 (Fig. 4b), possibly because of the larger tendency of the reactions in this model to form methylketene, as explained above. Acetone mole fractions are lower with $\sim 4 \times 10^{-4}$ (Fig. 4c) and show formation closer to the burner than for the primary intermediates, potentially indicating that the pathway is dominated by the recombination of acetyl with methyl radicals in a third-body reaction. The models severely under-predict acetone 
formation. It should be noted, that its isomer propanal was detected in only very small amount in the PI-MBMS measurements where it could in principle be unambiguously separated by acetone due to the high energy resolution. Also propanal formation is kinetically unlikely because of a much higher activation energy for an addition to the carbonyl C-atom.
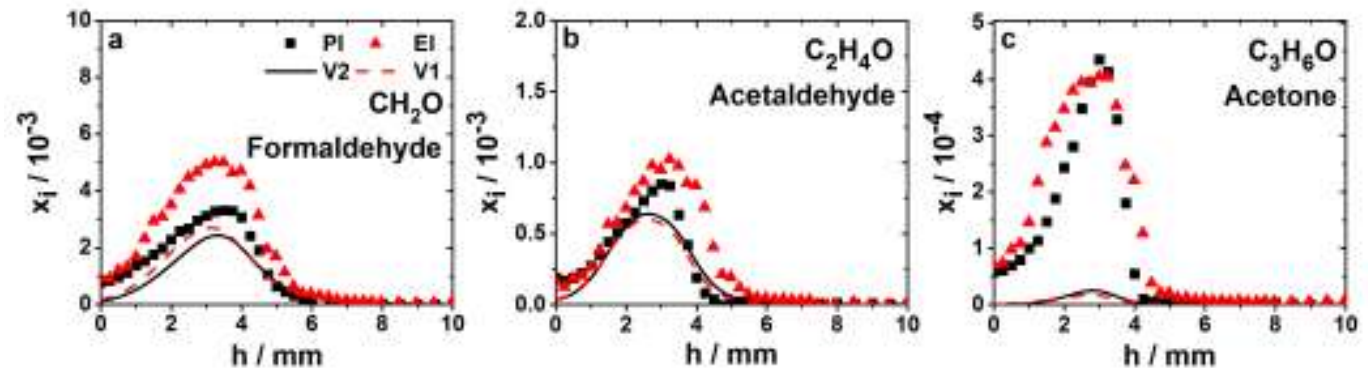

Figure 4: Mole fraction profiles of selected oxygenated species. Symbols: PI- and ElMBMS experiments, solid line: simulation with Version2; dashed line: Version1.

2-Butanone's fuel structure exhibits a C2-hydrocarbon sequence, and higher hydrocarbons are thus formed by radical recombination. Propyne $\left(\mathrm{C}_{3} \mathrm{H}_{4}\right)$ as a representative C3-species attains a mole fraction of $\sim 3 \times 10^{-4}$ (separated by PI-MBMS), and the C4-hydrocarbon with the highest concentration of $\sim 6.6 \times 10^{-4}$ is 1 -butene $\left(\mathrm{C}_{4} \mathrm{H}_{8}\right.$, measured by PI-MBMS) (see Table S2). Some intermediates typically identified as soot precursors are given in Fig. 5 . While the acetylene concentration is almost $2 \%$, higher molecular species including propargyl $\left(\mathrm{C}_{3} \mathrm{H}_{3}\right)$, 1,3-butadiyne $\left(\mathrm{C}_{4} \mathrm{H}_{2}\right)$, and 1-butene-3-yne $\left(\mathrm{C}_{4} \mathrm{H}_{4}\right)$ are present at the $10^{-4}$ levels, and 1,3-butadiene $\left(\mathrm{C}_{4} \mathrm{H}_{6}\right)$ and cyclopentadiene $\left(\mathrm{C}_{5} \mathrm{H}_{6}\right)$ are in the low ppm region. The potential of 2-butanone to form higher molecular species is thus limited, not unexpectedly, as oxygenated fuels have a lower soot formation tendency [4], a result in good agreement with those by Lemaire et al. [34] and McEnally et al [35]. The unsatisfactory prediction of 1,3-butadiene seems somewhat surprising, but it is used to the significant uncertainties in the formation reactions of 1,3-butadiene from the fuel; also the 
consumption reactions of 1,3-butadiene are not as precisely known as those for the corresponding alkane, butane.
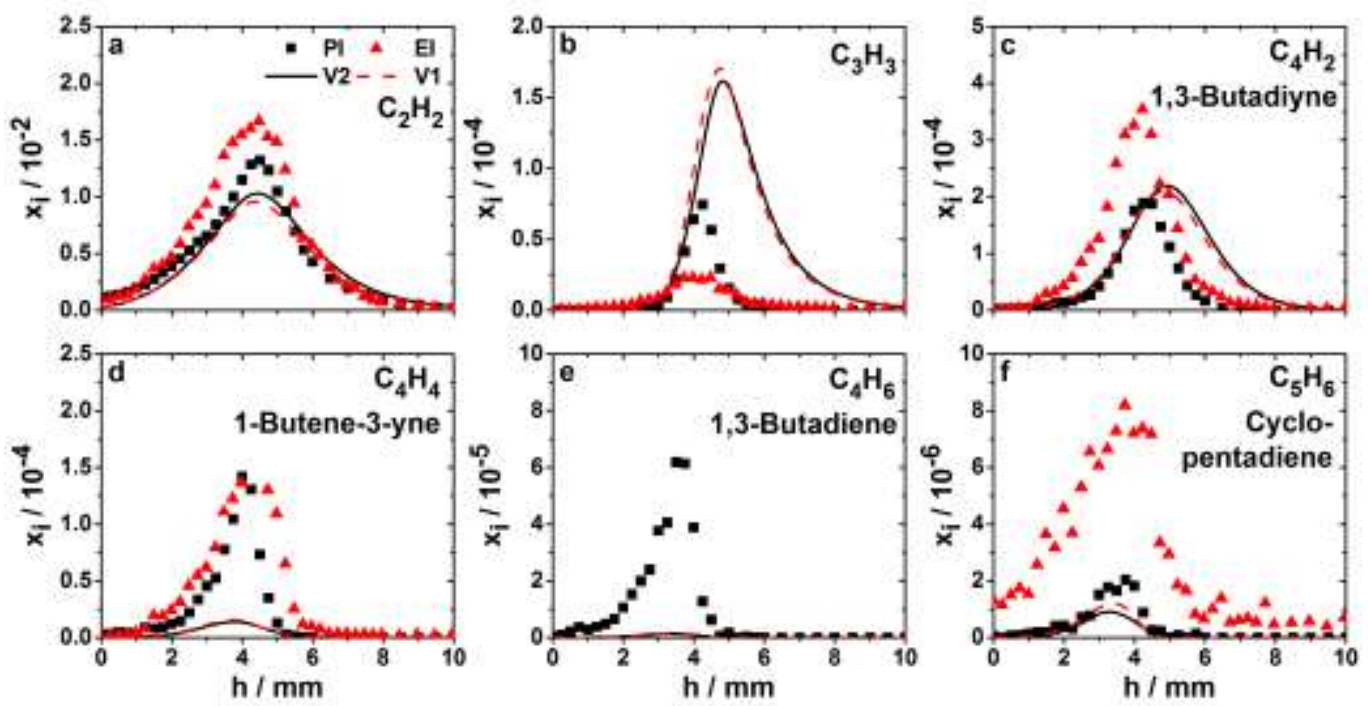

Figure 5: Mole fraction profiles of selected soot precursors. Symbols: PI- and El-MBMS experiments, solid line: simulation with Version2; dashed line: Version1. 1,3-Butadiene was identified, separated and quantified from PI-MBMS.

Table 1 compares mole fractions of selected oxygenated intermediates and soot precursors to those found under comparable conditions in flames of some representative biofuel types, including several furanics, alcohols, and small esters. Minor differences in equivalence ratio (1.6 or 1.7) don't have a significant effect on the trends shown in this table. In this comparison, part of which has been discussed before in an analysis of furan and its derivatives as potential cellulosic biofuels [36], 2-butanone shows the lowest overall concentrations for species that could contribute to potentially hazardous volatile emissions, underlining its attraction as a fuel also from this perspective.

\section{Summary and perspectives}

Experimental results for a laminar premixed low-pressure 2-butanone flame were obtained providing a large array of quantitative species profiles from two independent MBMS 
experiments, including isomer separation from PI-MBMS. Very good agreement between both measurements was found. MVK, a highly toxic species, was unambiguously detected as an intermediate species formed in significant quantities. Further oxygenated species including formaldehyde, acetaldehyde, ketene, and acetone were seen to be formed in quantities similar or lower than for selected oxygenated fuels under comparable conditions. Several soot precursors were also identified in comparatively low concentrations, underlining the potential of 2-butanone as a clean biofuel.

The experiments were initially examined and compared with simulations using an recently developed detailed chemical kinetic model [23]. The current understanding of the oxidation of 2-butanone under premixed flame conditions is limited, especially in its capacity to predict MVK. Despite changes made in the model to improve its performance including the present under-prediction of MVK, further kinetic work is required, with particular importance seen of reactions controlling the consumption of the 2 -butanoyl radicals such as the $\beta$ scission reactions.

Discrepancies are likely related to uncertainties with the assignment of some rate constants. Rate constants for radical $\mathrm{C}-\mathrm{C} \beta$-scission reactions would benefit from a direct calculation to improve predictions of intermediate species. Also, uncertainties exist within the base mechanism; for example, the methylketene mechanism is currently only addressed in a semi-detailed fashion. The present data, providing quantitative mole fractions for about 45 species with very good agreement between two independent determinations, may prove useful in further critical examinations of the related reaction chemistry.

\section{Acknowledgements}

The authors thank Muneeb Kurshid, Sara Jo Taylor, Bin Yang, Thomas Bierkandt, Kai Moshammer and Nils Hansen of the ALS "Flame Team" for participation in the PI-MBMS 
measurements. The authors from the physico-chemical fundamentals of combustion (PCFC) acknowledge the support of the cluster of excellence "Tailor Made Fuels from Biomass", which is funded by the Excellence Initiative of the German federal and state governments to promote science and research at German universities. The Advanced Light Source is supported by the Director, Office of Science, Office of Basic Energy Sciences, of the U.S. Department of Energy under Contract No. DE-AC02-05CH11231. The work at King Abdullah University of Science and Technology was funded by competitive research funding awarded to the Clean Combustion Research Center. 


\section{References}

[1] S.M. Sarathy, P. Oßwald, N. Hansen, K. Kohse-Höinghaus, Prog. Energy Combust. Sci. 44 (2014) 40-102.

[2] K. Kohse-Höinghaus, P. Oßwald, T.A. Cool, T. Kasper, N. Hansen, F. Qi, C.K. Westbrook, P.R. Westmoreland, Angew. Chem. Int. Ed. 49 (21) (2010) 3572-3597.

[3] L.S. Tran, B. Sirjean, P.-A. Glaude, R. Fournet, F. Battin-Leclerc, Energy 43 (1) (2012) 4-18.

[4] C.K. Westbrook, W.J. Pitz, H.J. Curran, J. Phys. Chem. A 110 (21) (2006) 69126922.

[5] M.S. Graboski, R.L. McCormick, Prog. Energy Combust. Sci. 24 (2) (1998) 125-164.

[6] G. Fontaras, G. Karavalakis, M. Kousoulidou, L. Ntziachristos, E. Bakeas, S. Stournas, Z. Samaras, Environ. Pollut. 158 (7) (2010) 2496-2503.

[7] R. Ballesteros, J.J. Hernández, J. Guillén-Flores, Fuel 95 (2012) 136-145.

[8] F.M.A. Geilen, B. Engendahl, A. Harwardt, W. Marquardt, J. Klankermayer, W. Leitner, Angew. Chem. Int. Ed. 49 (32) (2010) 5510-5514.

[9] D.M. Alonso, J.Q. Bond, J.A. Dumesic, Green Chem. 12 (9) (2010) 1493-1513.

[10] F.N. Egolfopoulos, N. Hansen, Y. Ju, K. Kohse-Höinghaus, C.K. Law, F. Qi, Prog. Energy Combust. Sci. 43 (2014) 36-67.

[11] F. Qi, Proc. Combust. Inst. 34 (2013) 33-63.

[12] A. Multer, N. McGraw, K. Hohn, P. Vadlani, Ind. Eng. Chem. Res. 52 (1) (2013) 5660.

[13] U.S. National Library of Medicine, available at <http://toxnet.nlm.nih.gov/>.

[14] Sebastian Heger, personal communication, Feb 09, 2016, Aachen.

[15] F. Hoppe, U. Burke, M. Thewes, K.A. Heufer, F. Kremer, S. Pischinger, Fuel 167 (2016) 106-117.

[16] V. Decottignies, L. Gasnot, J.F. Pauwels, Combust. Flame 130 (3) (2002) 225-240.

[17] Z. Serinyel, G. Black, H.J. Curran, J.M. Simmie, Combust. Sci. Technol. 182 (4-6) (2010) 574-587.

[18] J. Mendes, C.-W. Zhou, H.J. Curran, J. Phys. Chem. A 117 (22) (2013) 4515-4525.

[19] C.-W. Zhou, J.M. Simmie, H.J. Curran, Phys. Chem. Chem. Phys. 13 (23) (2011) 11175-11192.

[20] N. Sebbar, J.W. Bozzelli, H. Bockhorn, Z. Phys. Chem. 225 (9-10) (2011) 993-1018.

[21] K.-Y. Lam, W. Ren, S.H. Pyun, A. Farooq, D.F. Davidson, R.K. Hanson, Proc. Combust. Inst. 34 (2013) 607-615.

[22] J. Badra, A.E. Elwardany, F. Khaled, S.S. Vasu, A. Farooq, Combust. Flame 161 (3) (2014) 725-734.

[23] U. Burke, J. Beeckmann, W.A. Kopp, Y. Uygun, H. Olivier, K. Leonhard, H. Pitsch, K.A. Heufer, Combust. Flame, accepted 2016, doi:10.1016/j.combustflame.2016.03.001.

[24] P. Oßwald, H. Güldenberg, K. Kohse-Höinghaus, B. Yang, T. Yuan, F. Qi, Combust. Flame 158 (1) (2011) 2-15.

[25] T. Kasper, P. Oßwald, U. Struckmeier, K. Kohse-Höinghaus, C.A. Taatjes, J. Wang, T.A. Cool, M.E. Law, A. Morel, P.R. Westmoreland, Combust. Flame 156 (6) (2009) $1181-1201$.

[26] J.C. Biordi, Prog. Energy Combust. Sci. 3 (3) (1977) 151-173.

[27] T.A. Cool, A. Mcllroy, F. Qi, P.R. Westmoreland, L. Poisson, D.S. Peterka, M. Ahmed, Rev. Sci. Instrum. 76 (9) (2005) 94102. 
[28] X. Yang, D. Felsmann, N. Kurimoto, J. Krüger, T. Wada, T. Tan, E.A. Carter, K. Kohse-Höinghaus, Y. Ju, Proc. Combust. Inst. 35 (2015) 491-498.

[29] S.M. Burke, W. Metcalfe, O. Herbinet, F. Battin-Leclerc, F.M. Haas, J. Santner, F.L. Dryer, H.J. Curran, Combust. Flame 161 (11) (2014) 2765-2784.

[30] S.M. Burke, U. Burke, R. Mc Donagh, O. Mathieu, I. Osorio, C. Keesee, A. Morones, E.L. Petersen, W. Wang, T.A. DeVerter, M.A. Oehlschlaeger, B. Rhodes, R.K. Hanson, D.F. Davidson, B.W. Weber, C.-J. Sung, J. Santner, Y. Ju, F.M. Haas, F.L. Dryer, E.N. Volkov, E.J. Nilsson, A.A. Konnov, M. Alrefae, F. Khaled, A. Farooq, P. Dirrenberger, P.-A. Glaude, F. Battin-Leclerc, H.J. Curran, Combust. Flame 162 (2) (2015) 296-314.

[31] J. Bugler, K.P. Somers, E.J. Silke, H.J. Curran, J. Phys. Chem. A 119 (28) (2015) 7510-7527.

[32] K.P. Somers, J.M. Simmie, W.K. Metcalfe, H.J. Curran, Phys. Chem. Chem. Phys. 16 (11) (2014) 5349-5367.

[33] LOGESoft, available at <http://loge.se/Products/LOGE_Products.html>.

[34] R. Lemaire, D. Lapalme, P. Seers, Combust. Flame 162 (9) (2015) 3140-3155.

[35] C.S. McEnally, L.D. Pfefferle, Environ. Sci. Technol. 45 (6) (2011) 2498-2503.

[36] C. Togbé, L.-S. Tran, D. Liu, D. Felsmann, P. Oßwald, P.-A. Glaude, B. Sirjean, R. Fournet, F. Battin-Leclerc, K. Kohse-Höinghaus, Combust. Flame 161 (3) (2014) 780-797.

[37] D. Liu, C. Togbé, L.-S. Tran, D. Felsmann, P. Oßwald, P. Nau, J. Koppmann, A. Lackner, P.-A. Glaude, B. Sirjean, R. Fournet, F. Battin-Leclerc, K. KohseHöinghaus, Combust. Flame 161 (3) (2014) 748-765.

[38] L.-S. Tran, C. Togbé, D. Liu, D. Felsmann, P. Oßwald, P.-A. Glaude, R. Fournet, B. Sirjean, F. Battin-Leclerc, K. Kohse-Höinghaus, Combust. Flame 161 (3) (2014) 766-779.

[39] T.S. Kasper, P. Oßwald, M. Kamphus, K. Kohse-Höinghaus, Combust. Flame 150 (3) (2007) 220-231.

[40] B. Yang, C.K. Westbrook, T.A. Cool, N. Hansen, K. Kohse-Höinghaus, Z. Phys. Chem 225 (11-12) (2011) 1293-1314. 
Table 1: Peak mole fractions for some key intermediates and products in laminar premixed flames of selected biofuels adapted from [36]; MEK=2-butanone, $M F=2$-methylfuran, $\mathrm{DMF}=2,5$-dimethylfuran, $\mathrm{EtOH}=$ ethanol, $\mathrm{BuOH}=1$-butanol, $\mathrm{MP}=$ =methyl propanoate, $\mathrm{p}$ pressure in mbar.

\begin{tabular}{|c|c|c|c|c|c|c|c|}
\hline Fuel & $\mathrm{MEK}^{1}$ & Furan [37] & $\overline{M F}[38]$ & DMF [36] & EtOH [39] & $\mathrm{BuOH}[24]$ & $\mathrm{MP}$ [40] \\
\hline$\Phi / A r \% / p$ & $1.6 / 50 / 40$ & $1.7 / 50 / 40$ & $1.7 / 50 / 40$ & $1.7 / 50 / 40$ & $1.0 / 25 / 50$ & $1.7 / 25 / 40$ & $1.5 / 50 / 40$ \\
\hline Acetylene & $1.3 \mathrm{E}-02$ & $3.5 \mathrm{E}-02$ & $3.3 \mathrm{E}-02$ & $3.1 \mathrm{E}-02$ & $4.8 E-04$ & $3.1 \mathrm{E}-02$ & 1.1E-02 \\
\hline Ethylene & $2.2 \mathrm{E}-02$ & $6.7 \mathrm{E}-03$ & $8.0 \mathrm{E}-03$ & $7.1 \mathrm{E}-03$ & $2.1 \mathrm{E}-03$ & 3.1E-02 & $1.8 \mathrm{E}-02$ \\
\hline Propargyl & $7.5 \mathrm{E}-05$ & $1.0 \mathrm{E}-04$ & $2.5 \mathrm{E}-04$ & $3.6 \mathrm{E}-04$ & - & $3.4 \mathrm{E}-04$ & 4.2E-04 \\
\hline 1,3-Butadiene & $6.2 \mathrm{E}-05$ & $4.6 \mathrm{E}-04$ & $2.0 \mathrm{E}-04$ & 2.7E-03 & - & $7.5 \mathrm{E}-04$ & $4.0 \mathrm{E}-05$ \\
\hline $\begin{array}{l}\text { 1,3-Cyclo- } \\
\text { pentadiene }\end{array}$ & $2.1 \mathrm{E}-06$ & $1.0 \mathrm{E}-04$ & $2.5 \mathrm{E}-03$ & $2.5 \mathrm{E}-03$ & - & 7.5E-04 & 3.4E-06 \\
\hline Benzene & 3.3E-05 & $1.3 \mathrm{E}-04$ & $1.0 \mathrm{E}-03$ & $1.0 \mathrm{E}-03$ & - & $4.5 E-05$ & - \\
\hline Formaldehyde & 3.3E-03 & $3.8 \mathrm{E}-03$ & $2.9 \mathrm{E}-03$ & $2.9 \mathrm{E}-03$ & $5.1 \mathrm{E}-03$ & 7.1E-03 & 2.0E-02 \\
\hline Acetaldehyde $^{2}$ & $8.5 \mathrm{E}-04$ & $3.2 \mathrm{E}-03$ & $6.7 \mathrm{E}-04$ & $6.7 \mathrm{E}-04$ & $4.8 \mathrm{E}-03$ & 1.7E-02 & $2.6 \mathrm{E}-04$ \\
\hline Acrolein & - & $2.5 \mathrm{E}-03$ & $8.5 \mathrm{E}-04$ & $8.5 \mathrm{E}-04$ & - & - & 1.0E-03 \\
\hline Methanol & $1.5 \mathrm{E}-04$ & $4.4 \mathrm{E}-04$ & $3.1 \mathrm{E}-04$ & $3.1 \mathrm{E}-04$ & - & - & 1.1E-03 \\
\hline Phenol & - & $9.7 \mathrm{E}-06$ & $9.1 \mathrm{E}-04$ & $9.1 \mathrm{E}-04$ & - & - & - \\
\hline MVK & $4.2 \mathrm{E}-04$ & $3.4 \mathrm{E}-05$ & $3.3 \mathrm{E}-04$ & $9.7 \mathrm{E}-04$ & - & - & - \\
\hline
\end{tabular}

\footnotetext{
- : Not available

${ }^{1}$ Present results from PI-MBMS.

${ }^{2}$ Possibly sum of acetaldehyde and vinyl alcohol.
} 


\section{Figure Captions}

Figure 1: Main species profiles; symbols: filled: EI-MBMS, open: PI-MBMS, solid line: simulation with Version2.

Figure 2: Reaction flow analysis for the flame condition; net consumption $(h=0-20 \mathrm{~mm})$ is shown as percentages next to the arrows.

Figure 3: Mole fraction profiles of first detectable intermediates after $\mathrm{H}$-abstraction and $\beta$-scission. Symbols: PI- and EI-MBMS experiments, solid line: simulation with Version2; dashed line: Version1.

Figure 4: Mole fraction profiles of selected oxygenated species. Symbols: $\mathrm{PI}$ - and $\mathrm{El}-$ MBMS experiments, solid line: simulation with Version2; dashed line: Version1.

Figure 5: Mole fraction profiles of selected soot precursors. Symbols: PI- and EI-MBMS experiments, solid line: simulation with Version2; dashed line: Version1. 1,3-Butadiene was identified, separated and quantified from PI-MBMS. 